\title{
DESTINO AMBIENTAL FOTOQUÍMICO DO ANTIBIÓTICO SULFAMETOXAZOL EM MEIO AQUOSO
}

\author{
B. BARBERATO ${ }^{1}$, A. M. LASTRE-ACOSTA ${ }^{2}$ e A.C. S. C. TEIXEIRA ${ }^{3}$ \\ ${ }^{1}$ Aluna do PQI/EPUSP \\ ${ }^{2}$ Pós-Doutoranda do PQI/EPUSP \\ ${ }^{3}$ Professor do PQI/EPUSP - Escola Politécnica - Departamento de Engenharia Química - \\ Universidade de São Paulo \\ E-mail para contato: acscteix@usp.br
}

\begin{abstract}
RESUMO - Poluentes emergentes, como antibióticos, pesticidas, hormônios e fármacos, vêm sendo detectados não só em águas superficiais como em águas destinadas ao consumo humano. Uma vez administrados terapeuticamente, tais compostos não são totalmente metabolizados e muitas vezes não são eliminados por completo nas estações de tratamento de esgoto e de águas residuais, podendo afetar a qualidade de corpos d'água e a comunidade microbiana aí presente. Os efeitos dessa classe de fármacos não são totalmente conhecidos e sua persistência em águas superficiais depende, entre outros fatores, de sua transformação devido a processos bióticos e abióticos. Assim, o conhecimento de sua persistência no ambiente aquático é essencial para avaliar seus potenciais impactos. Neste trabalho, apresentam-se resultados parciais da fotodegradação do antibiótico sulfametoxazol em meio aquoso, como resultado da interação desse contaminante com a radiação solar (fotólise direta) e da reação com espécies reativas intermediárias (RI), particularmente radicais hidroxila $\left(\mathrm{HO}^{\bullet}\right)$ (fotólise indireta).
\end{abstract}

\section{INTRODUÇÃO}

Contaminantes chamados emergentes ou poluentes de preocupação emergente estão sendo detectados não só em águas superficiais como em águas destinadas ao consumo. No Brasil, foram detectados em amostras de água da bacia hidrográfica de Jacarepaguá, Rio de Janeiro (Lopes et al., 2016) e na baía de Santos, Santos-SP, em concentrações de ng L ${ }^{-1}$ até $\mu \mathrm{g}$ $\mathrm{L}^{-1}$ (Pereira et al., 2016). A persistência de compostos orgânicos em águas superficiais depende, entre outros fatores, de sua cinética de transformação devido a processos bióticos e abióticos. A combinação dos conhecimentos já adquiridos acerca da degradação fotoquímica mediada por radiação solar e de novos experimentos em laboratório são fundamentais para se determinar taxas de fotólise direta e indireta de compostos, o que levará a um entendimento mais completo da fotodegradação, destino ambiental e impacto no ambiente de fármacos poluentes.

\subsection{Antibióticos}

Os antibióticos são fundamentais na prevenção e no tratamento de infecções microbianas, interrompendo o crescimento e a reprodução de bactérias patogênicas e/ou causando a morte bacteriana. Por isso, têm o potencial de interferir na comunidade microbiana 
presente em esgotos. Assim sendo, resíduos desses fármacos, quando presentes no meio ambiente, tornam-se um risco à saúde humana, principalmente pelo fato de contribuírem para aumento da resistência bacteriana.

Levando em consideração que não há na literatura científica trabalhos sobre o destino ambiental fotoquímico do antibiótico sulfametoxazol (sulfonamida) em matrizes aquosas, este trabalho trata de estudar a degradação desse fármaco (entre outros), mediada por radiação solar simulada, como resultado de reações fotoquímicas e ação de espécies reativas intermediárias oxidantes $(\mathrm{RI})$, particularmente radicais hidroxila $\left(\mathrm{HO}^{\bullet}\right)$, geradas a partir da interação da luz solar com componentes orgânicos e inorgânicos (tais como matéria orgânica dissolvida, nitrato e nitrito) presentes em corpos d'água.

\subsection{Destino Ambiental Fotoquímico}

A degradação fotoquímica promovida pela radiação solar e a ação de espécies reativas oxidantes têm papel fundamental no destino de poluentes em águas naturais. A fotólise se baseia na dissociação ou decomposição de compostos químicos pela luz natural ou artificial e pode ser direta ou indireta. Na fotólise direta, os compostos orgânicos absorvem radiação UV e podem reagir com os componentes da matriz aquosa ou sofrer auto-decomposição. A fotólise indireta, por sua vez, envolve a oxidação por espécies reativas, como oxigênio singlete $\left({ }^{1} \mathrm{O}_{2}\right)$, radicais hidroxila e hidroperoxila $\left(\mathrm{HO}^{\bullet}, \mathrm{HO}_{2}{ }^{\bullet}\right)$, além de estados triplete da matéria orgânica cromofórica dissolvida $\left({ }^{3} \mathrm{CDOM}^{*}\right)$ (Giokas e Vlessidis, 2007).

A interação da radiação UV/VIS com a matéria ocorre com os orbitais atômicos (AO) ou moleculares (MO), promovendo elétrons para estados eletronicamente excitados. A primeira etapa do processo fotoquímico é chamada de absorção (Oppenländer, 2003), quando ocorre a promoção de um elétron do estado fundamental para um estado excitado (indicado por *). $\mathrm{O}$ estado eletrônico excitado $\mathrm{AB}^{*}$ possui maior energia e pode retornar ao seu estado fundamental por processos físicos radiativos e não radiativos. As equações 1 a 4 resumem as etapas mais comuns de processos iniciados por estados excitados, resultando na quebra de ligações e fotólise de compostos:

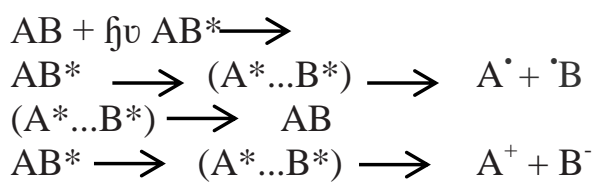

O rendimento quântico é uma medida da eficiência fotônica de uma reação fotoquímica, ou seja, o número de mols de um produto formado, ou reagente consumido, por número de mols de fótons absorvidos.

\subsection{Constantes Cinéticas da Reação entre os Antibióticos e as RI}

O conhecimento das constantes cinéticas de segunda ordem das reações entre os antibióticos e as espécies reativas intermediárias (RI) é essencial para prever as taxas de fotólise indireta. De acordo com o método de competição cinética, detalhado por Shemer et al. (2006), o poluente compete pelas espécies reativas de oxigênio (ROS) com um composto de referência em uma mistura contendo o poluente, uma fonte do ROS em questão e um 
composto de referência de reatividade conhecida com o ROS e as constantes são calculadas por:

$$
k_{\text {cont }, R I}=\left(\frac{k_{\text {cont }(o b s)}-k_{\text {fotólise direta,cont }}}{k_{\text {ref }(o b s)}}\right) * k_{\text {ref,RI }}
$$

Em que $k_{\text {fotólise direta }}$ é a constante de pseudo primeira-ordem para a fotólise direta do contaminante; $k_{c o n t, R I}$ é a constante da taxa de reação entre o antibiótico contaminante e a RI $\left(\mathrm{HO}^{\bullet}\right) ; k_{\text {cont }(o b s)}$ é a constante de pseudo primeira-ordem para a degradação do antibiótico contaminante, medida experimentalmente; $k_{\text {ref (obs) }}$ é a constante de pseudo primeira-ordem para a remoção do composto de referência, medida experimentalmente; $k_{r e f, R I}$ é a constante da taxa de reação entre a RI e o composto de referência. O composto de referência (molécula-sonda) utilizado neste trabalho é o ácido $p$-clorobenzoico ( $p \mathrm{CBA}$ ), empregado para determinação das constantes cinéticas de segunda ordem entre os fármacos estudados e radicais $\mathrm{HO}^{\bullet}\left(k_{p C B A, \mathrm{OH}} \bullet=5 \times 10^{9} \mathrm{~L} \mathrm{~mol}^{-1} \mathrm{~s}^{-1}\right)$ (Elovitz e Von Guten, 1999).

\section{MATERIAIS E MÉTODOS}

Para o preparo das soluções, utilizou-se água Milli-Q. O pH foi ajustado ao valor inicial desejado com soluções de $\mathrm{H}_{2} \mathrm{SO}_{4} 0,1 \mathrm{~mol} \mathrm{~L}^{-1}(80 \% \mathrm{v} / \mathrm{v}$ Scharlau) ou de NaOH0,1 mol $\mathrm{L}^{-1}(99 \%$ Sigma-Aldrich). A Tabela 1 mostra outros reagentes utilizados no trabalho, sua qualidade e procedência.

Tabela 1 -Reagentes empregados no estudo de fotodegradação do antibiótico SMX.

\begin{tabular}{ccc}
\hline Reagente & Qualidade & Fornecedor \\
\hline Metanol & HPLC & Merck \\
\hline Ácido $p$-clorobenzoico & $99 \%$ & Sigma-Aldrich \\
\hline Peróxido de hidrogênio & $30 \% \mathrm{w} / \mathrm{v}$ & Panreac \\
\hline Sulfametoxazol & $99,7 \%$ & Sigma-Aldrich \\
\hline
\end{tabular}

As soluções aquosas contendo o antibiótico sulfametoxazol (SMX) (10 mg $\left.\mathrm{L}^{-1}\right)$ foram irradiadas em simulador solar (Newport, modelo 91160), equipado com uma lâmpada de xenônio de até $450 \mathrm{~W}$ e filtro AM 1,5 global. Para o experimento de fotólise direta, as amostras foram irradiadas por 12 horas, sendo retiradas a cada 3 horas. Para o experimento de fotólise indireta, irradiadas por 4 horas, sendo retiradas pelo menos a cada 1 hora. As amostras foram irradiadas em vials e em duplicata, em seu $\mathrm{pH}$ natural e corrigido para 7 e mantidas a $25^{\circ} \mathrm{C}$ por banho termostático.

Os ensaios controle de hidrólise foram realizados a $25{ }^{\circ} \mathrm{C}$, em frascos mantidos sob agitação orbital constante de $100 \mathrm{rpm}$ em uma incubadora termostatizada da TECNAL (modelo TE-421). Ajustou-se o $\mathrm{pH}_{\text {inicial }}$ para os valores de 3, 5, 7 e 9. Os experimentos foram realizados em duplicatas e as amostras retiradas em diferentes tempos foram analisadas via HPLC.

A detecção e quantificação da concentração do antibiótico SMX e do composto de referência foram realizadas por meio de um sistema de cromatografia líquida de alta eficiência 
(HPLC) (Shimadzu, modelo 10AD), equipado com uma coluna RP18 (modelo Superspher100, dimensão $250 \mathrm{~mm} \times 4,6 \mathrm{~mm} ; 5 \mu \mathrm{m}$ ) e um detector UV/VIS (SPD-20A). Os métodos de análise dos compostos ácido $p$-clorobenzóico ( $p$ CBA) e sulfametoxazol (SMX) são apresentados na Tabela 2.

Tabela 2- Método de análise HPLC dos compostos, ácido $p$-clorobenzóico ( $p$ CBA) e sulfametoxazol (SMX).

\begin{tabular}{cccccc}
\hline Composto & Fase Móvel & $\begin{array}{c}\text { Porcentagem } \\
\text { dos eluentes }\end{array}$ & $\begin{array}{c}\text { Vazão } \\
\left(\mathbf{m L ~ m i n} \mathbf{~ m i n}^{-1}\right)\end{array}$ & $\begin{array}{c}\text { Comprimento } \\
\text { de onda (nm) }\end{array}$ & Referências \\
\hline SMX & $\begin{array}{c}\text { (A) metanol } \\
\text { (B) } \mathrm{H}_{2} \mathrm{O}+\text { ácido } \\
\text { acético } 1 \%\end{array}$ & $\begin{array}{c}0-20 \text { min: } 20 \% \\
\text { de } \mathrm{A}\end{array}$ & 1,0 & 267 & Cruz et al., 2010 \\
\hline \multirow{2}{*}{$\mathbf{C B A}$} & $\begin{array}{c}\text { (A) metanol } \\
\text { (B) } \mathrm{H}_{2} \mathrm{O}+\text { ácido } \\
\text { acético } 1 \%\end{array}$ & $\begin{array}{c}0-18 \text { min: } 50 \% \\
\text { de } \mathrm{A}\end{array}$ & 1,0 & 234 & Lester et al., 2013 \\
\hline
\end{tabular}

\section{RESULTADOSE DISCUSSÃO}

\subsection{Hidrólise em Solução Aquosa}

A Figura 1 permite observar que, independentemente do valor do $\mathrm{pH}$, a solução apresenta estabilidade química, não sendo constatada reação de hidrólise do SMX no tempo total considerado.

Figura 1 - Resultados dos ensaios de hidrólise de SMX. $[\mathrm{SMX}]_{0}=(11,4 \pm 0,1) \mathrm{mg} \mathrm{L}^{-1}$.

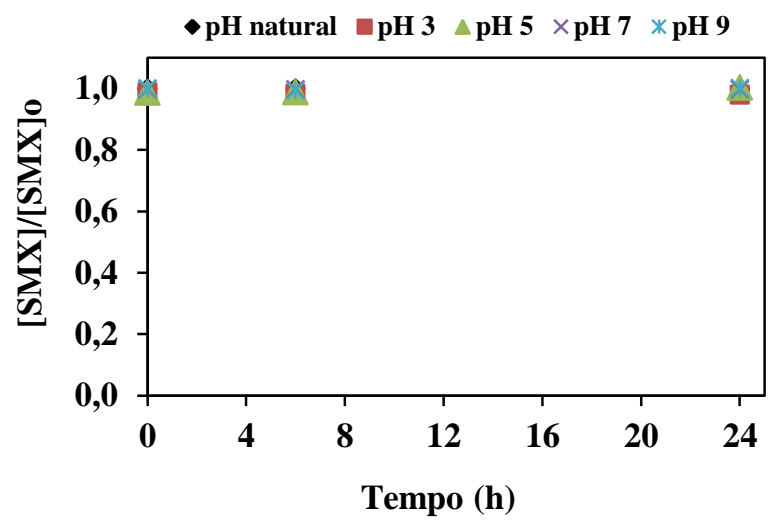

\subsection{Fotólise Direta em Solução Aquosa}

Experimentos realizados com $[\mathrm{SMX}]_{0}=10 \mathrm{mg} \mathrm{L}^{-1} \mathrm{em}$ matriz aquosa indicaram $15 \%$ de remoção do antibiótico após 12 horas de exposição à luz solar simulada em $\mathrm{pH}$ natural $(\mathrm{pH}$ 5,2 ) e $5 \%$ em pH 7 (Figura 2). As constantes cinéticas de pseudo primeira-ordem da fotólise direta do sulfametoxazol, observadas experimentalmente, foram $0,01388 \mathrm{~h}^{-1}\left(=2,31 \times 10^{-4} \mathrm{~min}^{-}\right.$ $\left.{ }^{1}\right)$ para $\mathrm{pH}$ natural $(5,3)$ e $0,00702 \mathrm{~h}^{-1}\left(=1,17 \times 10^{-4} \mathrm{~min}^{-1}\right)$ para $\mathrm{pH} 7$. A diferença entre esses valores pode ser resultado de comportamentos fotoquímicos diferentes das formas neutra 
(prevalente em pH 5.3) e desprotonada (prevalente em pH 7) do SMX. Essa hipótese será verificada posteriormente.

Figura 2 - Fotólise direta e indireta de SMX sob luz solar simulada. $[\mathrm{SMX}]_{0}=$ $(11,5 \pm 0,5) \mathrm{mg} \mathrm{L}^{-1}$.

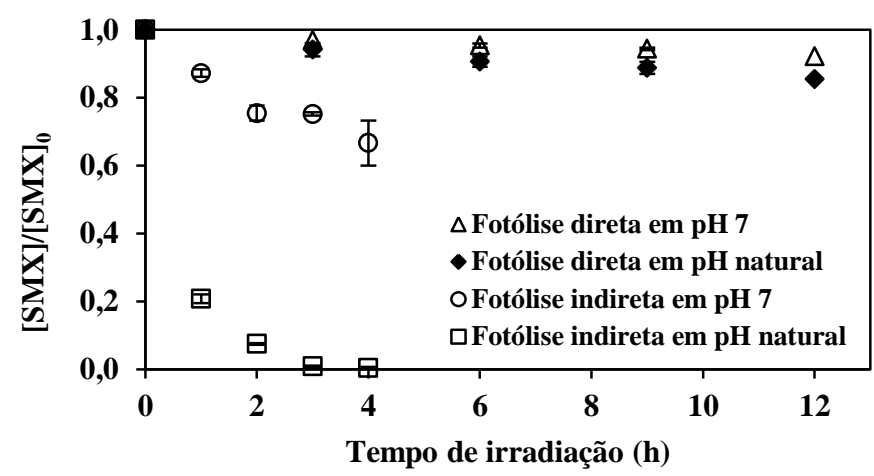

\subsection{Papel das RI na Fotólise do Sulfametoxazol}

A constante cinética de segunda ordem da reação entre o antibiótico e radicais hidroxila $\left(k_{\text {antibiótico,HO}}{ }^{\circ}\right)$ foi determinada usando o método de cinética competitiva descrito por Shemer et al. (2006) e utilizando peróxido de hidrogênio como fonte de radicais $\mathrm{HO}^{\bullet}$. Os resultados são apresentados na Figura 3.

Figura 3-Fotólise indireta de SMX sob luz solar simulada em uma matriz aquosa contendo pCBA como composto de referência e peróxido de hidrogênio $\left(50 \mathrm{mmol} \mathrm{L}^{-1}\right)$ como fonte de radicais $\mathrm{HO}^{\bullet} .[\mathrm{SMX}]_{0}=(11,5 \pm 0,2) \mathrm{mg} \mathrm{L}^{-1} ;[p \mathrm{CBPA}]_{0}=(9,5 \pm 0,2) \mathrm{mg} \mathrm{L}^{-1}$.
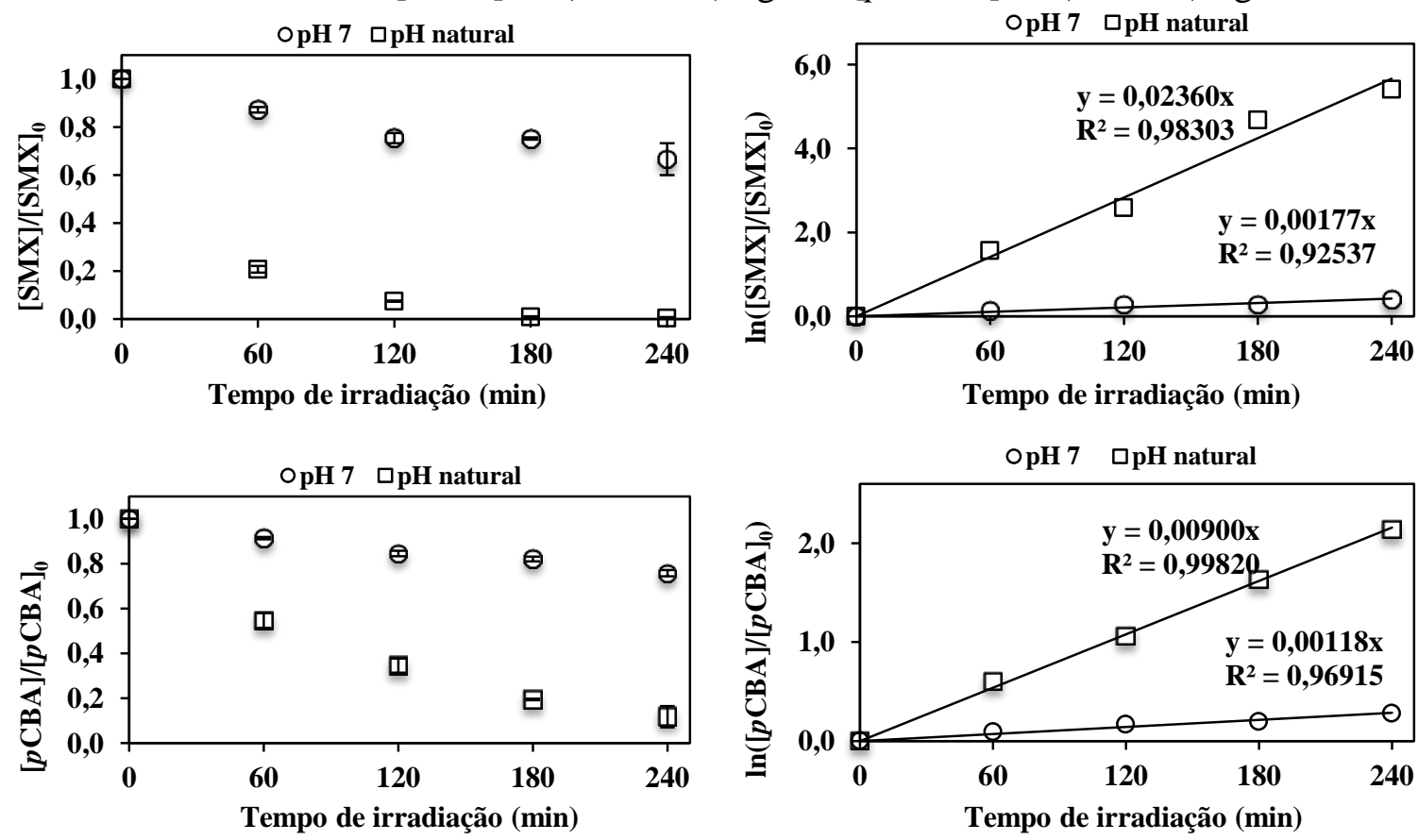
As variações de $[\mathrm{SMX}] /[\mathrm{SMX}]_{0}$ para a degradação de SMX resultante da fotólise foram bem ajustadas por comportamentos de pseudo primeira-ordem, com constantes de $1,77 \times 10^{-3} \mathrm{~min}^{-1}$ (coeficiente de determinação, $\left.R^{2}=0,925\right)$ e $2,36 \times 10^{-2} \min ^{-1}\left(R^{2}=0,983\right.$ ), para pH 7 e natural, respectivamente. Em consonância com os resultados apresentados na Figura 2, esses valores são notavelmente superiores aos obtidos para a fotólise direta, quais sejam, $1,17 \times 10^{-4}\left(R^{2}=0,955\right)$ e $2,31 \times 10^{-4}\left(R^{2}=0,950\right) \mathrm{min}^{-1} \mathrm{em} \mathrm{pH} 7 \mathrm{e} \mathrm{pH}$ natural, respectivamente.

Por outro lado, sabe-se que a lei de velocidade de degradação de contaminantes orgânicos por radicais $\mathrm{HO}^{\bullet}$ segue comportamento de segunda ordem. Assim, de acordo com o método de cinética competitiva (Shemer et al. 2006) e a Equação 5, e utilizando as constantes de fotólise direta, foi possível obter os valores experimentais das constantes cinéticas de segunda ordem da reação entre o antibiótico e radicais $\mathrm{HO}^{\bullet}\left(k_{\mathrm{SMX}, \mathrm{HO}}{ }^{\circ}\right)$. Essas constantes são iguais a $1,30 \times 10^{10} \mathrm{~L} \mathrm{~mol}^{-1} \mathrm{~s}^{-1}$ para $\mathrm{pH}$ natural $(5,3)$ e $7,00 \times 10^{9} \mathrm{~L} \mathrm{~mol}^{-1} \mathrm{~s}^{-1}$ para $\mathrm{pH} 7$.

\section{CONCLUSÕES PARCIAIS}

Este estudo confirma que a degradação fotoinduzida do SMX sob luz solar é menos importante e mostrou que o ataque das moléculas de SMX pelos radicais $\mathrm{HO}^{\bullet}$ é o mecanismo dominante envolvido na degradação do antibiótico em águas superficiais expostas à luz solar.

\section{REFERÊNCIAS}

CRUZ, L. H.; HENNING, F. G.; SANTOS, A. B.; PERALTA-ZAMORA, P. Degradação fotocatalítica de sulfametoxazol, trimetoprima e diclofenaco em solução aquosa. Quím. Nova, v. 33, p. 6, 2010.

GIOKAS, D. L.; VLESSIDIS, A. G. Application of a novel chemometric approach to the determination of aqueous photolysis rates of organic compounds in natural waters. Talanta, v. 71, p. 288, 2007.

LESTER, Y.; MAMANE, H.; ZUCKER, I.; AVISAR, D. Treating wastewater from a pharmaceutical formulation facility by biological process and ozone. Water Res., v. 47, 13, p. 4349, 2013.

LOPES, V. S. A.; RIENTE, R. R.; SILVA A.A.; TORQUILHO, D. F.; CARREIRA, R. S.; MARQUES, M. R. C. Development of a solid-phase extraction system modified for preconcentration of emerging contaminants in large sample volumes from rivers of the lagoon system in the city of Rio de Janeiro, Brazil. Mar. Poll. Bull., v. 110, p. 572, 2016.

OPPENLANDER, T. Photochemical Purification of Water and Air: Advanced Oxidation Processes (AOPs): Principles, Reaction Mechanisms, Reactor Concepts, Wiley-VCH, 2003.

PEREIRA C. D. S.; MARANHO, L.; CORTEZ, F. S.; PUSCDDU, F. H.; SANTOS, A. R; RIBEIRO, D. A.; CESAR, A.; GUIMERÃES, L. L. Occurrence of pharmaceuticals and cocaine in a Brazilian coastal zone. Sci. Tot. Environ., v. 548, p. 148-154, 2016.

SHEMER, H.; SHARPLESS, C. M.; ELOVITZ, M. S.; LINDEN, K. G. Relative rate constants of contaminant candidate list pesticides with hydroxyl radicals. Environ. Sci. Technol., v. 40, p. 4460, 2006. 